\title{
Erratum to: The effect of functional forms of nitrogen on fuel-NO $\mathrm{NO}_{x}$ emissions
}

\author{
Linghui Zhang • Dagen Su • Mingfeng Zhong
}

Published online: 5 March 2015

(C) Springer International Publishing Switzerland 2015

Erratum to: Environ Monit Assess(2015)187:4195

DOI: 10.1007/s10661-014-4195-6

Unfortunately, erroneous author affiliations were published in the article "The effect of functional forms of nitrogen on fuel- $\mathrm{NO}_{x}$ emissions".

The correct list of author affiliations is now shown below.

The online version of the original article can be found at http:// dx.doi.org/10.1007/s10661-014-4195-6.

L. Zhang $\cdot$ D. Su $(\bowtie) \cdot$ M. Zhong

School of Materials Science and Engineering, South China

University of Technology,

Guangzhou 510641, China

e-mail: dgsu@scut.edu.cn

L. Zhang

e-mail: zlh@jyu.edu.cn

L. Zhang

Jiaying University,

Meizhou 514015 Guangdong, China

e-mail: zlh@jyu.edu.cn 